\title{
Challenges of Human Resources Management in Project-based Organizations
}

\author{
1,2 Faculty of Economics, \\ Ghazni University, Ghazni City. \\ Afghanistan \\ *atta.jawad86@gmail.com
}

| Attaullah Jawad ${ }^{1, *} \mid$ Hameedullah Noori ${ }^{2}$ |

\begin{abstract}
Organizations are constantly under the influence of the environment they are operating in. The Industrial Revolution necessitated the establishment of long-lasting organizations with an emphasis on the stability of activities. However, undermining this principle, today's businesses and organizations have moved towards projectification. This has demoted permanent and longlasting activities in task-oriented organizations and transformed the meaning of many concepts such as financial management, human resource management, and knowledge management. Human resources management (HRM) is one of the areas of management that has undergone major changes in project-based organizations (PBOs). Since this new nature of organizations and businesses has challenged the stability of HRM, PBOs must plan and develop alternative methods for HRM. This paper hence aims to introduce the concept of PBOs and different types of PBOs and then discuss how this new organizational structure affects and challenges HRM.

KEYWORDS

projectification; Human Resources Management (HRM); organizational structure; resource management
\end{abstract}

\section{INTRODUCTION}

HRM is one of the most important pillars of any organization because it can play a major role in any organizational success or failure; successful HRM can create a new competitive advantage or develop the existing competitive advantages (Bredin, 2008). In many organizations, HRM practices can affect the efficiency, experiences, and relationships of employees (Amit and Belcourt, 1999; Bredin et al., 2006) and direct organizational factors in a way to lead to organizational success (Guest, 2002; Winstanley and Woodall, 2000). Basics of HRM are largely based on structures that emphasize the stability of activities and the continuous presence of staff in the organization.

Today's organizations are mainly established based on the development of temporary and project-based structures that involve many people. Accordingly, some believe that "project" is the unit of measuring the amount of work done, the unit that is realized through the resources of a working team not merely one person or one company (Engwall et al., 2003). In other words, many companies are now going through a process called project-centrism, which aims to manage operations within a project to develop structures related to project management in an organization (Engwall et al., 2003). This new organizational structure and nature has changed many organizational practices such as financial management, contract management, and recruitment. For example, the recruitment policies of many organizational were traditionally based on employing normal individuals and then training them to gain the necessary qualifications for doing a task. However, many of today's organizations emphasize meritocracy and prefer to recruit and 
pay higher for more knowledgeable individuals for a short period to do part of their projects (March, 1995).

HRM practices, such as planning, recruitment, service compensation, development, and retention, have been further transformed in PBOs. It can be certainly stated that a few studies have dealt with this subject; moreover, the measurement of HRM efficiency in PBOs requires redefining concepts such as motivation, commitment, empowerment, satisfaction, and performance management. This paper hence aims to address some of the items mentioned above and discuss how they are estimated in PBOs.

\section{LITERATURE REVIEW}

Before the emergence of projectification, many argued that HRM should be aligned with organizational strategic planning and help the organization achieve its strategic goals. They also believed in integration, either vertical or horizontal, in all dimensions for this purpose (Bredin et al., 2006; Lengnick-Hall and Lengnick-Hall, 1988).

When an organization decides to begin the process of projectification and changes some of its short- and long-term plans, the organization should change its HRM policies, processes, and activities to integrate them with the new structure (Gareis, 1990). It is noteworthy that most HRM theories have been proposed for classical organizations in which dynamism is less important and there is an emphasis on fixed procedures based on specific job descriptions and rules (Wright and Boswell, 2002). Such theories will obviously face challenges to describe PBOs that are inherently dynamic and variable (Keegan et al., 2008).

Projects are temporary structures that form and eventually disappear within nontemporary organizations (Gareis, 2005). Accordingly, HRM may experience some changes with the beginning or termination of a project (Sydow et al., 2004). The frequency of these changes can initiate a score of HRM activities, including recruitment and appointment of work force to different organizational levels (Sydow et al., 2004). Since such changes also reduce the transparency of organizational boundaries, the use of similar management practices for different projects cannot properly lead the organization to achieve its goals (Turner, 2006). This lack of transparency extends to all pillars of projects in a way that leaves the organization with uncertainties in costs, revenues, and achievements (manufacture and supply of products and services). However, the degree of uncertainty depends on the duration of projects; for instance, construction projects, which usually last for a long time, face fewer uncertainties but the projects related to the development of IT products, which have a shorter lifespan, may experience more uncertainties (Turner, 2006). Although HRM faces more difficulties and challenges under uncertain conditions, uncertainty is an area of research less addressed by HRM researchers.

PBOs usually have a portfolio of different projects and, as a result, deal with a wide range of activities at the same time. Moreover, employees may work on several projects simultaneously and play a different role in each of them. For example, one can be the executive manager of one project and the technical expert of another project (Guide, 2001). In some organizations, employees may have a permanent job position while taking a part in one or more organizational projects; for example, one can be the managing director of an organization while working as the financial director in a project. The allocation of resources to projects is a major source of conflicts in PBOs (Rau and Hyland, 2002). Additionally, there may be cases in which the management of activities related to several projects causes conflicts for employees.

PBOs have their specific culture that consists of empowerment of human resources (HR), teamwork, process-based management, and customer demand management (Keegan et al., 
2008). These pillars have originated from the need for competent and skilled staff with completive advantages to work in projects. Based on this need, organizations have to update their HRM to be in line with and highlight the most important aspects of their culture (Huemann et al., 2007).

The literature review indicates the need for further studies to specifically investigate HRM in PBOs. In fact, linking the non-hardware view of HRM with project management, which has a hardware view on HR, can help us achieve a balanced level of HRM in PBOs.

\section{Problem Statement}

PBOs always have challenges with HRM, even when running some areas in a non-projectbased manner and some others in a project-based manner, resulting in some organizational conflicts. Therefore, here we discuss HRM challenges of PBOs in order to help organizational managers reduce conflicts considering the risk of processes. In this section, a classification of PBOs will be provided and then HRM challenges of such organizations will be discussed.

\section{Classification of $\mathrm{PBO}$}

For exploring the roots of PBOs, two categories of such organizations should be reviewed. The first category includes organizations that have been established in recent years merely based on the projectification approach. These organizations, which have never experienced the task-based structure, are called the original PBOs. This kind of structure is regarded as "macro-structure" in the literature on projectification. The second category involves older organizations that have recently tried to shift from a task-based approach to a project-based approach. In fact, they have gone or going through a process of "project-centrism". In fact, after managing the processes by the task-based structure for years, they now have to incorporate the project-based structure into the task-based structure (which is in contrast with the project-based structure in many cases). Most of today's organizations and businesses fall into this category. The transition from task-centrism to projectification is much more difficult than establishing a new PBO from the very beginning because all the processes, procedures, and job descriptions that employees are accustomed to should be changed. In this case, we will observe organizational resistance at different levels. This structure is referred to as the "micro-structure" in the literature on projectification.

\section{HRM challenges in PBOs}

HRM challenges in PBOs can be addressed from two viewpoints; the top-down view, which focuses on organizational interests, and the bottom-up view, which emphasizes the interests of people involved in the organization. Based on the former view, some researchers argue that PBOs do not have enough time to train and develop HR because such organizations deal with heavier workloads due to the diversity of projects they are involved in (Hobday, 2000). This can eventually demotivate the staff and cause further unpleasant consequences. The diversity of specialties needed for the advancement of projects can jeopardize the organizational development path and lead to the nurture of specialists who have a superficial understanding of development.

Another HRM challenge in PBOs is the changing structure of jobs (Larsen, 2002). PBOs are now developing job packages in order to recruit individuals who are knowledgeable and skilled in the right range of disciplines needed for their projects (Allen et al., 1995), rather than defining single-task jobs. Some believe that interdisciplinary activities will be shortly one of the interests of PBOs. 
Another major challenge of such organizations is how to allocate work force to projects. The allocation of work force to projects and measurement of their performance is one of the areas that have been less regarded in HRM studies, and there are a few standard systems for this purpose (Engwall and Jerbrant, 2003).

The learning effect is another area of HRM that can be influenced in PBOs. According to the learning effect, the long-term process of developing a skill can reduce the duration of activities. However, PBOs do not allow the staff to engage in long-term learning activities during short-term projects (Packendorff, 2002).

The identification of HRM changes in PBOs from the bottom-top view also requires an investigation into the effects of projectification on HR (Packendorff, 2002). Projectification transforms both the working aspects of individuals and their personal lives. Accordingly, changes in the nature, time, and payment of traditional jobs can transform the lifestyles and social culture associated with these occupations. Many project-oriented professionals now focus more on the output of their activities and no longer sell their time to organizations, resulting in the development of a culture of self-marketing.

The three major factors that PBOs consider for recruiting their staff are knowledge, creativity, and teamwork, which are less taken into account in classical organizations (Sisson and Storey, 2000). The more responsibilities of employees in PBOs, compared to those in task-oriented organizations, imposes great psychological pressure on employees of PBOs and increases absenteeism due to diseases caused by occupational stress and high workload. Although many people welcome project-based activities because of their abilities, some others oppose this working structure because they lack the special abilities needed to work in such structures; in fact, since they are not empowered and trained enough to reach the level of innovation and knowledge required by PBOs, they may be removed from the circle of activities over time, resulting in a sense of insecurity. Moreover, some research projects whose success rate is not much high can exacerbate this sense of insecurity, because the research team may fail to achieve the desired results despite doing their best. The main duty of HRM units in PBOs should be to somehow manage these conflicts and find a solution to them (Redman and Wilkinson, 2009).

Another challenge of PBOs is the need for increasing the speed of recruitment. This process usually takes a long time in task-oriented organizations, whereas it should be accomplished as soon as possible in PBOs because of the short lifespan of projects. HRM units of PBOs also need to form specialized teams to quickly provide the work force needed for the projects through a network of specialists (Redman and Wilkinson, 2009).

\section{RESULTS AND DISCUSSION}

\section{Challenges of Projectification in Afghans' Organizations}

The main challenges of HRM in PBOs will be discussed here based on the abovementioned items. HRM challenges may vary from country to country depending on the culture, laws, and labor market. These challenges may be greater in some countries, due to some facilitators, or smaller, because of the lack of such facilitators. Here we discuss all these challenges in Afghans' organizations.

\section{Development of Job Description and Authorities under Existing Laws}

Project managers in PBOs should have complete authority; under ideal conditions, the authorities of project managers should be as much those of senior managers. However, it is sometimes difficult for HRM units to delegate all the job descriptions and authorizes of senior managers to project managers, especially due to some legal considerations. Some Afghans' laws for public organizations insist on non-delegation of authorities, whereas this 
kind of authority classification is considered a barrier to the advancement of projects in project-based structures. This has counteracted all projectification efforts in public organizations, which are overseen by several regulatory bodies. Moreover, the laws on financial accounting and spending have added to the complexity of this challenge. Therefore, without amendments to the existing laws and regulations, there will be no hope that Afghan's organizations, especially public ones, approach a project-based structure.

\section{Human Resources Development (HRD) Planning}

HRM units of most Afghans' organizations do not play their main role, rather they engage in managing administrative affairs. As a result, they fail to fulfill the most important tasks of HRM such as planning, development, and performance management. The temporary appointment of individuals to job positions exacerbates this problem in Afghan's organizations that are trying to move towards projectification. Accordingly, most organizations take no responsibility for and do not try to develop the skills and abilities of the part-time staff working on a project-based basis. This reduces employee loyalty to and trust in the organization and causes problems such as incomplete delivery of projects and outputs; something which has been observed more frequently in recent years due to the declining revenues of organizations and firms.

\section{Recruitment and Allocation of Manpower to Projects and Increasing Relevant Activities} Recruitment is one of the main challenges of HRM in PBOs. HRM units in such organizations should prepare a list of required qualifications and then recruit work force based on this list. PBOs have to deal with much more of such activities and processes, compared to task-oriented organizations, because they need to recruit specialized work force. However, the time-consuming legal procedure of recruitment in public organizations cannot be well matched with the short lifespan of projects. On the other hand, there is currently no network of specialists to help HRM units quickly find and requite the specialized work force they need for their projects. This is, however, related to the vocational education system that not only provides the necessary training courses and develops a competency model but also issues professional certificates for a wide range of specialties. Although such vocational and professional systems have been established in some fields such as engineering, law, and medicine, most fields of study and disciplines have not yet reached this level of maturity and professionalism. Therefore, HRM units of PBOs still face serious challenges with planning and recruitment.

\section{Manpower Dismissal after the Completion of Projects and Increasing Relevant Activities}

PBOs face more challenges than classical task-oriented organizations do with work force dismissal and its relevant activities, similar to the recruitment and allocation of work force. After the completion of a project in PBOs, work force is allocated to another project or considered to be invited for future projects, appointed to administrative positions, or totally dismissed to leave the organization. Considering the Afghanistan's law and the current economic status of this country, the last choice is less common, and organizations are required to pay their work force under the rules as long as they are their employees but are not involved in any project. However, the recruitment of full-time work force in some organizations can be a barrier to moving towards projectification in the future.

Another problem in this regard is that some public and even private organizations lack the authority to dismiss incompetent work force who does not create value for the organization. This not only doubles the expenditures but also demotivates the competent work force involved in projects. Therefore, HRM units in PBOs should come up with 
strategies and solutions, such as developing various methods and contracts of cooperation, to solve this problem and reduce unnecessary costs considering legal and organizational conditions.

\section{Development of Job Packages to Replace Traditional Jobs}

As mentioned earlier, the work force in PBOs acquires a wider range of skills and knowledge due to the variety of projects implemented by such organizations. The work force in PBOs also tries to engage in interdisciplinary and extracurricular activities to be able to take different roles in projects. Such organizations hence develop job packages instead of dealing with single-dimensional jobs. Many organizations now need to recruit interdisciplinary experts and directors who can help the organization in various dimensions. Moreover, the unawareness of most of today's project managers of standards of project management, costing, resource leveling, and other topics of project management can cause problems for the completion of projects. As a result, another HRM challenge in PBOs is the development of job packages and their required job descriptions and competencies.

\section{Project-based Payment Methods}

An important point that HRM units of PBOs should always consider is their costing system. The allocation of HR costs to projects is one of the main challenges of HRM units. This problem consists of two parts: one is how to price services, work force output, and the other is indirect HR costing. Many organizations pay their work force based on the duration of works and projects, but work force efficiency should be also taken into account in this regard to lead the organization in the right direction. There are now some organizations that fail to properly manage their projects despite the constant presence of their staff. It can be hence stated that one of the main challenges of HRM in PBOs is the development of hardware and software infrastructure to collect data needed to allocate HR costs to projects.

\section{Occupational Stress of Workforce}

Work force in PBOs is more accountable because they enjoy a wide range of authorities to advance the projects, whereas the work force of lower ranks in classical task-oriented organizations is not much accountable for its performance. There are employees in some Afghans' organizations who are also completely indifferent to the issues related to their area of responsibility. However, a group of work force working for PBOs may try to evade any responsibility because they are concerned about possible failures or unavailability of necessary facilities to advance the projects. The higher stress level of project teams resulting from the greater range of their responsibility can negatively affect their performance. The stress level may vary from project to project; for example, project teams may under more stress in research projects in which the success rate is lower. In public organizations that have never experienced such conditions, some of the work force may resist the organizational movement towards a project-based structure. If HRM units of such organizations fail to organize an appropriate system of motivation to reduce the resistance, they will face major challenges with the projectification process.

\section{HR Communication and Experience Sharing}

Knowledge management (KM) is an important and vital issue that PBOs deal with. A major part of $\mathrm{KM}$ is the sharing of experiences gained from projects. Due to the temporary presence of specialists in projects or such organizations, a challenge of HRM in PBOs is to collect and share the experiences of specialists during the projects. The repeated 
recruitment and dismissal processes and the lack of executive authority to extract the acquired knowledge of work force and specialists during the project comprise another challenge of PBOs. Organizations can take advantage of the experiences and knowledge gained from previous projects to identify and address the possible risks of their future projects. For this process, organizations should extract and archive the useful records of their previous projects.

\section{HR Motivation and Satisfaction}

When the organization delegates more responsibilities to the work force and tries to institutionalize the accountability system, there is a need for incentives to further encourage the work force to work to realize projectification. The existing general laws and regulations on work force rewards and incentives are sometimes in contrast with the incentive system of organizations. The Afghans' laws do not allow many public organizations to offer their staff cash or non-cash bonuses. This also applies to the delayed payment penalties, as it is not possible to reduce payments to the work force in some cases. Another problem is the lack of clear criteria for determining the rewards and bonuses; for example, payments based on self-reporting results and outputs can demotivate the work force and make them indifferent to the effective advancement of projects. As a result, HRM units of organizations should revise the existing laws and regulations to develop an efficient system of incentives and rewards and a system of service compensation, with an emphasis on its variables parts, in order to ensure that the organization is moving towards performance-based payments.

\section{CONCLUSION}

The transition from classical task-oriented organizations to PBOs in Afghanistan is still in its infancy. Accordingly, senior managers of many organizations are now motivated to define and pursue their activities in the form of projects in order to increase their productivity. Although this is an unavoidable process that all organizations should go through, it is necessary for all organizations to first fulfill the requirements and resolve the challenges of turning into a PBO. If these issues remain unaddressed, projectification not only does not increase productivity but also imposes more cost on the organization. Since HRM is one of the most important organizational factors that can facilitate the acceptance of projectification, organizations should pay special attention to their HRM units and try to resolve their problems and challenges. This paper first introduced major HRM challenges, in general, and then discuss each of them with an emphasis on Afghans' organizations. The content can hence help managers identify possible challenges and plan to resolve them.

\section{REFERENCES}

Allen, T. J., Katz, R. J. R., \& Management, D. (1995). The project-oriented engineer: A dilemma for human resource management. 25(2), 129-140.

Amit, R., \& Belcourt, M. (1999). Human resources management processes: a valuecreating source of competitive advantage. European Management Journal, 17(2), 174-181

Bredin, K. (2008). People capability of project-based organisations: A conceptual framework. International Journal of Project Management, 26(5), 566-576.

Bredin, K., Söderlund, J. J. R., \& Management, d. (2006). HRM and project intensification in R\&D based companies: a study of Volvo Car Corporation and AstraZeneca. 36(5), 467-485

Engwall, M., \& Jerbrant, A. J. I. j. o. p. m. (2003). The resource allocation syndrome: the prime challenge of multi-project management? , 21(6), 403-409. 
Engwall, M., Steinthorsson, R. S., \& Söderholm, A. (2003). Temporary organizing: a Viking approach to project management research.

Gareis. (2005). Happy Projects!, Vienna. In: Manz Verlag 8. Gareis, R. (1990). Handbook of management by projects: Manz.

Guest, D. J. T. j. o. i. r. (2002). Human resource management, corporate performance and employee wellbeing: Building the worker into HRM. 44(3), 335-358.

Guide, A. (2001). Project Management Body of Knowledge (PMBOK® GUIDE). Paper presented at the Project Management Institute 11. Hobday, M. (2000). The projectbased organisation: an ideal form for managing complex products and systems? , 29(78), 871-893.

Huemann, M., Keegan, A., \& Turner, J. R. (2007). Human resource management in the projectoriented company: A review. 25(3), 315-323.

Keegan, A., Turner, J. R., \& Huemann, M. (2008). Managing human resources in the project-based organization.

Larsen, H. H. (2002). Oticon: Unorthodox Project-Based Management and Careers in a" Spaghetti Organization". 25(4), 324-335.

Lengnick-Hall, C. A., \& Lengnick-Hall, M. L. (1988). Strategic human resources management: A review of the literature and a proposed typology. 13(3), 454-470.

March, J. G (1995). The future, disposable organizations and the rigidities of imagination. 2(3-4), 427-440.

Packendorff, J. (2002). The temporary society and its enemies: Projects from an individual perspective. 39-58.

Rau, B. L., \& Hyland, M.M. (2002). Role conflict and flexible work arrangements: The effects on applicant attraction. 55(1), 111-136.

Redman, T., \& Wilkinson, A. (2009). Contemporary human resource management: Text and cases: Pearson Education.

Sisson, K., \& Storey, J. (2000). Realities of Human Resource Management: Managing the Employment Relationship: McGraw-Hill Education (UK).

Sydow, J., Lindkvist, L., \& DeFillippi, R. (2004). Project-based organizations, embeddedness and repositories of knowledge. In: Sage Publications Sage CA: Thousand Oaks, CA.

Turner, J. R. (2006). Towards a theory of project management: The nature of the project governance and project management. 2(24), 93-95.

Winstanley, D., \& Woodall, J. J (2000). The ethical dimension of human resource management. 10(2), 5-20.

Wright, P. M., \& Boswell, W. R. J. (2002). Desegregating HRM: A review and synthesis of micro and macro human resource management research. 28(3), 247-276. 